\title{
The Construction of China's Manufacturing Innovation System with the Influence of the Internet
}

\author{
Guo Jia ${ }^{1,2}$, Gan Yong ${ }^{3}$, Yan Jianlin ${ }^{1}$, Lv Tong ${ }^{1}$ \\ 1. The CAE Centre for Strategic Studies, Beijing 100088, China \\ 2. School of Materials Science and Engineering, Tsinghua University, Beijing 100084, China \\ 3. Chinese Academy of Engineering, Beijing 100088, China
}

\begin{abstract}
The new generation of information technology, which is characterized by the Internet and big data, is having a profound impact on the innovation system of the manufacturing industry. The authors of this paper analyze the construction demand of the manufacturing innovation system in terms of generic technology supply, technical supply method, and the system of cooperative innovation between the industry, universities, and academic research. The construction of generic technology research, a development base, and a technical supply platform will help in promoting the construction of an innovation network and the cultivation of an innovation ecology.
\end{abstract}

Keywords: Internet; new generation of information technology; manufacturing; innovation system

\section{Introduction}

China is an emerging industrial economy with a large manufacturing. According to the United Nations Industrial Development Organization, China's manufacturing value added in 2015 was USD 299.98 billion at constant 2010 prices, amounting to $33 \%$ of the total gross domestic product. China's competitive industrial performance ranks fifth in the world. Since reforming and opening up, China has established a complete and independent manufacturing system. The manufacturing industry also greatly assists domestic and international economic and social development [1].

Innovation is an endogenous force driving the development of the manufacturing industry. It plays an important role in improving production efficiency, upgrading and transforming technical equipment, and perfecting industrial structure. Today, the new generation of information technology is deeply intertwined with the manufacturing industry. Industrial production auxiliary software is used in production, consumption, and other productive circulation. Technological innovation in the manufacturing industry has led to several trends, like the cross-fusion of technology in multiple fields, mutual infiltration in different sections in the innovation chain, and coordination of the innovation network [2]. All of the above bring strategic opportunities to the manufacturing innovation system construction at the later stage of industrialization.

\section{The impact of the Internet on the innovation system construction of the manufacturing industry}

The Internet can make radical changes in the flow, range, speed, and cost of information. All intermediate value links based on information asymmetry will be gradually subverted or marginalized. Therefore, the Internet can lower trade costs, deepen the division of labor, and increase labor productivity. Currently, the Internet is deeply intertwined with the manufacturing industry, and the whole manufacturing value chain, including

Received date: April 25, 2017; Revised date: May 12, 2017

Corresponding author: Gan Yong, Chinese Academy of Engineering, Academician. Major research field is new metallurgical material. E-mail: gany@cae.cn.

Funding program: CAE Advisory Project "Research on Manufacturing Power Strategy (Phase II)" (2015-ZD-15)

Chinese version: Strategic Study of CAE 2017, 19 (3): 095-099

Cited item: Guo Jia et al. The Construction of Manufacturing Innovation System Influenced by Internet. Strategic Study of CAE, https://doi.org/10.15302/ J-SSCAE-2017.03.014 
research and development, design, production, sales and service, will be re-defined. First, there is the deep integration of products and services, where the core value of many products has transferred from the products themselves to their service. Second, manufacturing enterprises allow businesses to survive by utilizing the Internet. There isn't just a longitudinal integration of the supply chain, but also a transverse one, and the supply chain as a whole shows a trend towards the integration of the networking ecological chain [3]. The technological innovation system of the manufacturing industry produces new features by changing the industry.

\subsection{The platform economy}

The Internet has gradually pushed enterprises towards the platform economy. Platform economy is a commercial ecology system which is established and co-operated by multiple bodies, and where they share the resources and benefits [4]. All the participants can survive and enjoy prosperity together on a forceful platform. With the development of the industry, the platform has become the dominant factor determining the order of industry development. Competition between the platform and the ecosphere will form a new commercial competition pattern. Through platform economy, innovative bodies can provide customized services like technology acquisition, technology industrialization, industry organizing services, and so on. Platform economy can increase profits and promote research and development, spreading the industrialization of technology.

A network coordinative manufacturing platform is a typical platform economy. Its participants coordinate in the way of member renting mode and make production and manufacturing decisions based on big data. Such a platform uses technology devices like the Internet, big data, and so on, to provide fair and reasonable services for the coordinated manufacturing and thus attract more participants. An American company, EDS, has used its product, evis.com, to build up a coordinated platform called ASP (Application Service Provider) [5]. Baogang Group has established a service platform called Ouyeel for the steel industry, covering trade, finance, logistics, data, and materials.

\subsection{Integrated innovation}

With the exponential growth of information technology and its deep integration with manufacturing, "building blocklike" integrated innovation is developing in an explosive way. Integrated innovation lays more emphasis on the parallelism of research, development, testing, and manufacturing, etc., shortens the research and development cycle of the product, and highlights the coordination of different innovative bodies. Integrated innovation doesn't simply list different achievements, but also pays attention to the interaction among different entities, as well as between the innovation system and the outside environment based on innovative achievements, and re-organizes all the factors (sub-systems) in different ways to form new products with new functions [6].

Typical cases of integrated innovation are smartphones and Tesla electric vehicles. Take the smartphone as an example. The smartphone itself is already an electronic integrated platform with multiple functions like communication, entertainment, and so on. Its modular production of software and hardware is mature. A whole machine manufacturer is normally the major entity in the production, research, and development of smartphones, which completes the industrial design, component design, software and hardware design, and controls the market positioning of the cellphones, like Apple or Samsung. By virtue of upstream and downstream industry chain resources, the whole machine manufacturer purchases its chips and functional components [7]. Therefore, three major entities are gathered in the innovation platform of smartphones. An independent hardware supplier provides the chips, batteries, and so on. A supplier with high research and development and integration ability organizes the research and development and assembles the finished product. Manufacturing companies are responsible for the general design and integrate all kinds of software systematically [8]. The structure of the three suppliers is shown in Fig. 1.

\subsection{Seamless and open innovation}

Seamless and open innovation refers to the full responsibility, where each innovation stage is connected seamlessly with iterative development and recycling. Clients are deeply involved at the stage of development idea collection. At the stage of product research and development, crowd-sourcing is introduced to cooperate with the clients seamlessly, which makes full use of the surplus cognitive ability of the clients. At the initial stage of product innovation, the most active user will push innovation forward and make the product "lead the users." During this process, network technology provides the technological innovation platform for crowd-sourcing, bridges the temporal and spatial gaps with clients, and lowers the cost and threshold for participation [9].

The research and development of MI phones is a representative case of seamless and open innovation. Users participate in the planning, design, development, testing, and issuing of MI phones. MI Phone Company will invite "early maniac users" to try out imperfect products and offer feedback. The Company uses a special mechanism in which it searches for, manages, and encourages leading clients and maniacs, both online and offline, as well as the efficient Internet platform, to allow the communication of information between enterprises and clients, achieve iterative development and recycling throughout the process of innovation, and eventually realize a seamless and open innovation pattern [9]. 


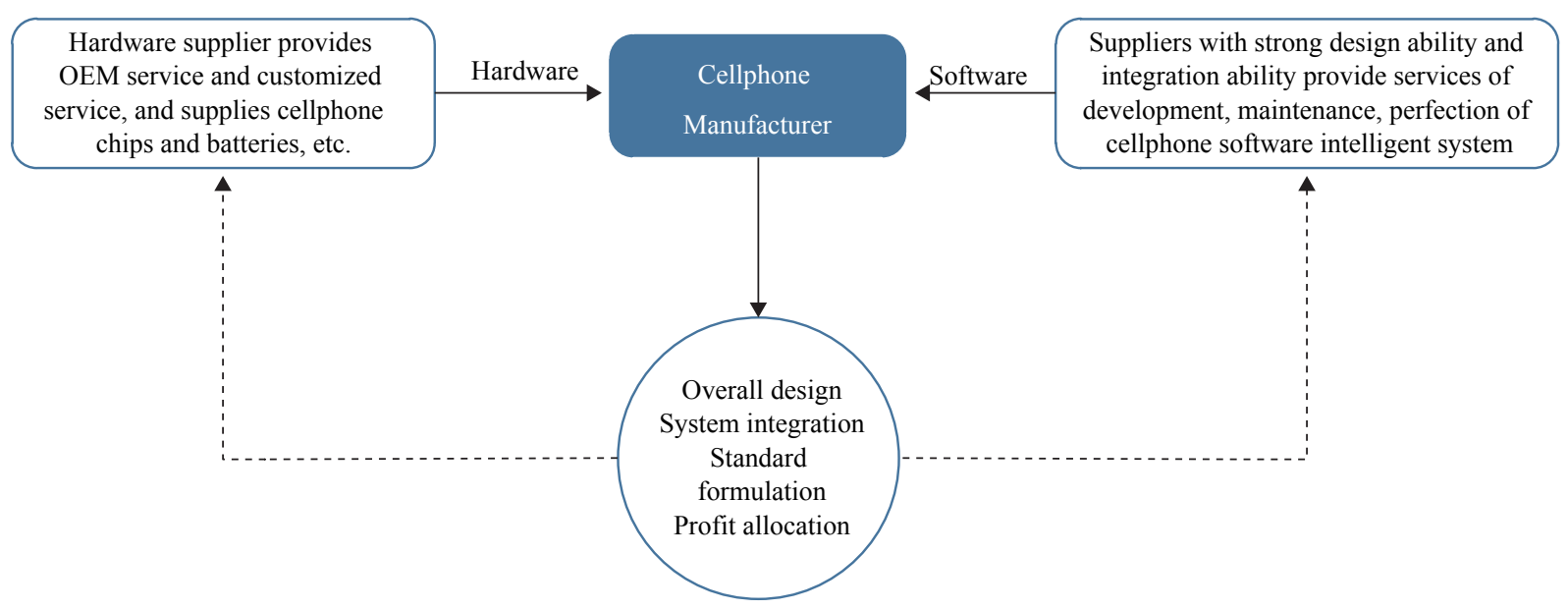

Fig. 1. Structure of three suppliers.

\section{The construction demand of manufacturing systems influenced by the Internet}

The Internet helps eliminate information asymmetry of innovation chains and quicken the flow of innovative factors. The innovation chain of the manufacturing industry keeps expanding and presents a dynamic, open, and networked development trend. In combination with the impact of the Internet on the innovation system of the manufacturing industry, we propose the following construction requests of the innovation system of the manufacturing industry influenced by the Internet, with a comprehensive analysis of the current conditions of the manufacturing industry.

\subsection{Integration of innovation resources with the Internet}

With the rapid development of Internet technology, technologies in sub-divisions of the manufacturing industry are merging and developing rapidly. Generic technology development in China has seriously lagged behind, greatly hindering China's manufacturing industry from transforming and upgrading. On one hand, the industry generic technology supporting system, which adjusts to the new tendencies of the manufacturing industry innovation system, is still under exploration and development, with many obstacles influencing and restraining sustainable and sound development. On the other hand, current industry generic technology supporting systems can scarcely adjust to the requests of promoting self-innovation ability, speeding up the transformation and upgrading of traditional industries, and cultivating and developing strategic emerging industries at the middle and late-stage industrial development.

Take the bearing as an example. There has initially been a supporting system of generic technology with multiple forms, channels, and levels, including major special projects, technology plans, key laboratories, a research center of engineering technology, the technology centers of the enterprises, and so on, offering theoretical and technological support for the technology structure optimization of the bearing industry. But manufacturing technology and equipment technology of the bearing industry develop slowly. Numerical control rate of vehicle processing is low. Automation level of grinding is low. These prevent domestic bearing products from satisfying the market's requirements on accuracy, properties, longevity, and reliance. Development of the bearing industry requires the use of the industrial Internet to integrate innovative carriers, offer basic theoretical generic technology and high-end bearing products and technologies, promote the intelligent and green development of the manufacturing technology of bearings, as well as the development of service-oriented and customized industry forms.

\subsection{Supply of offline services for R\&D by the Internet}

With the wide application of Internet technology, knowledge creation and application have integrated more closely. Emerging innovation patterns are springing up and a new hardware era, in which innovators and geeks are the significant innovation groups, is beginning. The Internet is capable of providing the technology innovation of the manufacturing industry with powerful R\&D tools, new research patterns and diversified network sharing, and long-distance coordination innovation platforms, as well as optimizing the technology supply methods.

Influenced by the traditional R\&D system, problems abound in the innovation system of manufacturing technology. For instance, innovation resources are scattered, the layout of the research and development centers is unreasonable; coupling effects in which the lines are driven by the points, and the facades are driven by the lines, are still in place. Problems like a lack of technological supply in the sub-divided industries of the manufacturing industry and weak self-research and self-development abilities in the key technologies of the industry are prominent. 
For example, Intel and Samsung take the leading positions in the high-end industrialized application of silicon materials, forming systematic international financing and client systems. They have established a perfect supporting system of materials, auxiliary parts, and assembly. China, however, lacks a technology platform, a market platform, or an information platform to support the high-end industrialized R\&D of silicon materials. It is difficult for the domestic silicon material industry to develop a joint force. Its production level remains at silicon slices and chips smaller than 8 inches, making up just $4.1 \%$ of global market share. Innovation resources in the silicon material industry are scattered, with a lack of valid technology supply. An effective method to get rid of this dilemma in the industry's development is for China to promote the flow of innovative factors and the spreading of technology with the Internet, to optimize the basic generic theories and high-end technology supply.

\subsection{Formation of the innovation network with the Internet}

Deep integration of high technology, in which information technology is the core, has given rise to a bunch of cluster innovation and subversive technologies. Information technology also allows the innovation system of the manufacturing industry to break through the boundary of region and organization, integrate the advantaged resources, like the institutes of scientific research and companies, etc., and form a coordinated and innovative network which crosses different departments and regions. An enterprise-oriented innovative system of production, learning, and research has been basically established in the manufacturing industry in China. Manufacturing enterprises are the input and output subjects of the technology innovation system, and play a leading role in technology spillover, especially under central enterprises' guidance of industry technology innovation. From 2009 to 2015 , R\&D input of enterprises with considerable scale in China took up around $75 \%$ of the national share. The authorization of the enterprise's job invention patent took up 37\% of the national share in 2009 , climbing to $52 \%$ in 2015 . Restrained by the assessment and evaluation mechanism of central enterprises and government intervention and so on, manufacturing enterprises are remarkably lacking in innovation motivation and will, and have low innovation efficiencies. Meanwhile, private enterprises also lack innovation.

Driving innovation resources to break through spatial and industrial restraints with Internet technology helps extend the innovation chain forward and backward, perfects the innovation system of production, bolsters learning and research in the manufacturing industry, and creates a cooperative and open innovation network. The proposals are: (1) the Internet should support the network development of the innovation system in the manufacturing industry. On one hand, more innovative bodies can gather through the Internet, and information and knowledge flow faster in the innovation network through Internet technological measures; on the other hand, Internet enterprises and individual economies integrate together, and the Internet will transform from production service towards the cross-integration of production and R\&D, and the central trend of the innovation network will be weakened. Therefore, it is necessary to create a policy environment in which there are benefits for enterprise innovation, and it is also necessary for the government to enhance the macroscopic control over the innovation system. (2) The Internet has hastened the more open and more coordinated development of innovation systems. Enterprises can use Internet technology to build up an open research and development network platform, share innovation resources, and connect innovation needs and technologies. In this way, enterprises can play their principal role to integrate and gather innovation factors. Enterprises should enhance their abilities in research and development, and it is especially necessary for central enterprises to clarify their responsibility for self-innovation, establish supervision and assessment mechanisms, and play an innovative and guiding role.

\section{Suggestions}

The Internet has profoundly changed the layout of the innovation system of the manufacturing industry. According to the construction requirements of the innovation systems of the manufacturing industry, it is necessary to come up with an innovation system according to the technology innovation features of ten major fields using two main lines, longitudinal and transverse, to integrate the current innovative resources, taking innovation carriers with entity operations as the base and forming highly unified targets of significant science, technology, and project tasks in the ten fields [11]. The innovation system of the manufacturing industry is constructed with cloud computing and Internet as the basic tools, and the public service platform and engineering data center as important supports. It will drive the pattern transformation of technology research and development, design, conversion, and industrialization, and serve the need of transforming and upgrading basic industries, and the cultivation and development of strategic and emerging industries in the next decade.

\subsection{The national innovation system construction of manufacturing industrial generic technology}

The Internet has made the manufacturing industry place more emphasis on the value increase of products. It is easier for innovative bodies to form geographically dispersed partnerships of coordinated R\&D on the innovative platform, and technology R\&D has transformed from single technology R\&D to generic technology and cutting-edge technology research. Thus, it is necessary to use the Internet to quicken the construction of R\&D institutes or new bases of generic technology in the manufactur- 
ing industry, to optimize resource allocation, and to form a close connection between the upstream and downstream. In the meantime, it is necessary to make use of the amplification effect and cluster effect of research institutes of generic technology innovation in the manufacturing industry. Establishment of research institutes of generic technology in the manufacturing industry should integrate currently existing high-level teams and R\&D platforms with remarkable research abilities, and a bunch of these teams and platforms should be selected as the innovative carriers.

Each research institute of generic technology innovation is comprised of several R\&D platforms. Each platform cooperates and coordinates according to the industry chain and innovation chain to form an innovation system of networking generic technology, to focus on the major direction of technology strategy concerning industry development in the future, to carry out key generic technology research, and to offer technology achievement sharing, shifting and spreading it to middle and small enterprises.

\subsection{Diversified technology supply methods}

Directed by market demand, it is necessary to select key industry fields, focus on important and cutting-edge technologies, establish a diversified innovation platform of production, learning and research, and constantly improve the national innovation system. Government should identify the concentration ratio of industries and establish innovation systems corresponding to the industry features in different fields. To be more specific, in fields where the industry concentration ratio is relatively high, such as the petrochemical industry, aerospace, power grids, and so on, it is necessary to construct a supporting system of industry technology innovation in which R\&D institutes of backbone enterprises are the major bodies. In industries with a lower industrial concentration ratio, such as machinery, steel, chemicals, and so on, it is necessary to use the Internet to establish an innovative technology supply pattern in combination with production, learning and research, in which the public research institutes are the main bodies. In the fields with an active market and emerging products which update rapidly, it is necessary to create a policy environment for technology achievement transformation, application, and industrialization by way of modern technology methods like big data, cloud computing, and network. It is also necessary to allow diversified bodies like colleges and universities, research institutes, middle and small enterprises, technical personnel, and so on, to play their roles in the technology supply of industrial innovation technology.

\subsection{Platform construction of the manufacturing industry}

In terms of construction of a big data information platform, China has launched a national big data strategy. However, the initial state of big data is relatively poor, with meager conditions, scattered data in the business, lack of legislation in the data industry and data protection, and so on. It is necessary to support it through funds to increase government support for soft power construction of the big data platform, and improve the efficiency, spread, and service of the big data platform. In addition, a high-quality third-party platform of cloud computing and big data should also be established.

The design and application platform of the manufacturing industry is also a platform where the government should play its role and enhance construction. Nowadays, modern components are characterized by miniaturization and intensity. The trend of the integration of materials and components is more and more obvious. Cooperation and coordination and integration of the upstream and downstream industries are more closely related. There is a trend of vertical spreading in the industry structure, and it is highly correlated with the equipment manufacturing industry, which is of vital importance in helping the establishment of a design and application platform, including finance, to lower the burden on the production enterprises and shorten the cycle of batch applications. Experimental application characterization technology systems are also included in the application and design platform, integrating the international standard system and promoting an exemplary project system of the application and so on [10].

\section{References}

[1] Strategic Consulting Committee on Upgrading of the National Manufacturing Sector. The Report on Made in China 2025 [M] Beijing: Publishing House of Electronics Industry, 2016. Chinese.

[2] He Y. The Thinking of Innovation Index System of China's Manufacturing [J]. China Industry Review, 2015 (9): 52-60. Chinese.

[3] Guo C Q. IT Will Redefine Manufacturing [J]. Shanghai Quality, 2013 (12): 9-13. Chinese.

[4] Strategic Consulting Committee on Upgrading of the National Manufacturing Sector, The CAE Centre for Strategic Studies. Interpretation of Made in China 2025-Report Set of Provincial and Ministerial Level Cadres' Symposium [M]. Beijing: Publishing House of Electronics Industry, 2016. Chinese.

[5] Zhang P, Zhou J H, Huang Y L, Wu L. Networked Collaborative Manufacturing System for Small and Medium Sized Mold Enterprises and Its Implementation [J]. Modern Manufacturing Engineering, 2006 (10): 140-143. Chinese.

[6] Zhang S H, Xue L. New Technology Innovation Management Paradigm-Integrative Innovation [J]. China Soft Science, 2012 (12): 6-22. Chinese.

[7] Liu M Y, Luo P L. The Comparative Research on Integration Innovation Mode of Brand Mobile Telephone and Modularity Innovation Mode of Mountain Fastness Mobile Telephone Based on the Long Tail Theory [J]. R\&D Management, 2010, 22(4): 1-9. Chinese.

[8] Studying Team of Stimulate the Vitality of Main Body of Innovation System. An Open Innovation Mode Based on Platform. [EB/ OL]. http://www.drc.gov.cn/n/20161215/1-224-2892323.htm, 
2016-12-15. Chinese.

[9] Dong J L, Chen J. Seamless Open Innovation: The Product Innovation Model of Xiaomi in the Internet Ecosystem [J]. Science Research Management, 2014 (12): 76-84. Chinese.

[10] Gan Y. Technological Development and Innovation of Basic Com- ponents, Basic Process and Basic Material for Manufacturing [J] China Industry Review, 2017 (1): 30-35. Chinese.

[11] Gan Y. The Problems and Solutions of Industry Technological Innovation System Construction [J]. China Industry Review, 2016 (10): 52-58. Chinese. 